\title{
Expert modelling
}

\section{Stuart Kininmonth, ${ }^{1,2,3}$ Steven Gray ${ }^{4}$ and Kasper Kok ${ }^{5}$}

\author{
${ }^{1}$ STOCKHOLM RESILIENCE CENTRE, STOCKHOLM UNIVERSITY, STOCKHOLM, SWEDEN \\ ${ }^{2}$ UNIVERSITY OF OSLO, OSLO, NORWAY \\ ${ }^{3}$ UNIVERSITY OF THE SOUTH PACIFIC, SUVA, FIJI ISLANDS \\ ${ }^{4}$ DEPARTMENT OF COMMUNITY SUSTAINABILITY, MICHIGAN STATE UNIVERSITY, EAST LANSING, MICHIGAN, USA \\ ${ }^{5}$ SOIL GEOGRAPHY AND LANDSCAPE GROUP, WAGENINGEN UNIVERSITY, WAGENINGEN, THE NETHERLANDS
}

\section{Key methods}

Bayesian networks, fuzzy cognitive maps

\section{Connections to other chapters}

Fuzzy cognitive maps can be combined with scenario studies (see Chapter 11), and Bayesian networks are based on simple network models (see Chapter 23).

\section{Introduction}

The term 'expert model' refers to a computer-based model that can mimic (or outperform) the decisions of a human expert (Jackson 1998). Given the broad nature of this definition, the variety of models that could be classified as 'expert' is substantial. In this chapter, we choose to focus on just two expert methods routinely used in understanding social-ecological systems (SES): Bayesian networks (also referred to as Bayesian belief networks, decision networks) and fuzzy cognitive maps. These two modelling approaches represent two conceptually and practically different ways to develop and apply expert models. At the more applied level, this class of models contributes to the growing toolbox of knowledge co-production methods, which allow the formalisation of stakeholder-generated knowledge as structured representations of complex systems. At the more conceptual level, this class of models belongs to the field of artificial intelligence (AI) and essentially uses inference techniques to process an explicit knowledge base to deduce novel information and increase our understanding of the complex system under study. Note that expert models are a broad category of very flexible tools and methods that are applied in all scientific disciplines. The use of fuzzy cognitive maps, for example, has been reported in close to 20000 scientific papers ranging from computer science, to medicine, to economics.

The justification for applying expert models in SES analysis is that these models allow researchers to understand the structure and dynamics of complex systems. Overall, the inherent complexity of these systems, which consist of multifaceted interactions between system elements, is difficult to understand without modelling tools. More specifically, diverse SES 


\begin{tabular}{|c|c|}
\hline \multicolumn{2}{|c|}{ SUMMARY TABLE: EXPERT MODELLING } \\
\hline DISCIPLINARY BACKGROUND & KNOWLEDGE TYPE \\
\hline $\begin{array}{l}\text { The methods in this chapter are derived } \\
\text { from or have most commonly been used in: } \\
\text { Mathematics, Statistics, Ecology, } \\
\text { Social Science }\end{array}$ & $\begin{array}{l}\text { The methods in this chapter are primarily } \\
\text { used to generate the following types of } \\
\text { knowledge: } \\
\text { - Descriptive } \\
\text { - Exploratory } \\
\text { - Explanatory }\end{array}$ \\
\hline RESEARCH APPROACH & PURPOSE OF METHOD \\
\hline $\begin{array}{l}\text { The methods in this chapter originate } \\
\text { from or most commonly adopt the } \\
\text { following research approaches: } \\
\text { - Analytical/objective } \\
\text { - Interpretive/subjective }\end{array}$ & $\begin{array}{l}\text { The most common purposes of using the } \\
\text { methods in this chapter are: } \\
\text { - System understanding } \\
\text { - Stakeholder engagement and } \\
\text { co-production } \\
\text { - Policy/decision support }\end{array}$ \\
\hline TEMPORAL DIMENSION & SYSTEMIC FEATURES AND PROCESSES \\
\hline $\begin{array}{l}\text { The methods in this chapter are most } \\
\text { commonly applied to the following } \\
\text { temporal dimensions: } \\
\text { - Present (typically within the last } \\
5-10 \text { years) } \\
\text { - Recent past (post-1700s) } \\
\text { - Future }\end{array}$ & \multirow{3}{*}{$\begin{array}{l}\text { While most methods can do many } \\
\text { things, the methods in this chapter are } \\
\text { particularly good (i.e. go-to methods) for } \\
\text { addressing the following: } \\
\text { - SES components and linkages } \\
\text { - Social-ecological dependence and } \\
\text { impact } \\
\text { - Multiple scales and levels or cross- } \\
\text { level interactions } \\
\text { - Regime shifts } \\
\text { - Evaluating policy options } \\
\text { - Exploring uncertainty }\end{array}$} \\
\hline SPATIAL DIMENSION & \\
\hline $\begin{array}{l}\text { The methods in this chapter are primarily } \\
\text { either or both: } \\
\text { - Non-spatial } \\
\text { - Explicitly spatial } \\
\text { The methods in this chapter are most } \\
\text { commonly applied at the following } \\
\text { spatial scales: } \\
\text { - Local } \\
\text { - Regional (provincial/state } \\
\text { to continental) } \\
\text { - Multiple places/sites around the world }\end{array}$ & \\
\hline
\end{tabular}


stakeholders, decision-makers and even scientists have fundamentally different perceptions of how these systems are structured. This disagreement and related miscommunication call for tools that can help our understanding while articulating and mapping these different perceptions. Expert models can help to both understand the complexity of systems and uncover the multiple perceptions of their functionality. Utilising conceptual understanding of the system, the starting point of expert models (Bayesian networks, fuzzy cognitive maps) is commonly cognitive maps, usually represented in the special form of semi-quantitative cognitive maps. These maps, constructed by individual experts or groups of experts (both local and scientific experts), are often used to represent a system of interacting elements visually. In this way both simple and more complex systems can be communicated through visuals with a fair degree of transparency of model assumptions and model structure while allowing for direct input from stakeholders on key relationships of SES.

Although expert models have only recently been applied to understanding SES, the background mathematical concepts that underlie these approaches have been around much longer. In fact, while expert models are now often squarely in the realm of AI and computer science, more basic mechanisms and formulations that allow them to work were developed before computers were commonplace. Bayesian inference, which is the fundamental construct behind Bayesian networks, was for example developed by Thomas Bayes in 1763 and then further developed by Judea Pearl (1982) with graphical models. These developments enabled the mathematical treatment of how one parameter relates to another (conditional inference), particularly when these correlations are connected across a network containing many parameters. The calculated probabilities across this network can be used to predict the probability of one event based on another.

Similarly, including probability and set theory in cognitive maps (Axelrod 1976) was advanced by Bart Kosko (1986) to create fuzzy cognitive maps. In the paper by Kosko, fuzzy cognitive maps are introduced as maps to employ a fuzzy or uncertain description of the causal link between two events. This uncertainty is embedded in a network of influential parameters so that the overall calculation of the causal probability can propagate across the network. Subsequent applications (Van Vliet, Kok and Veldkamp, 2010; Verkerk et al. 2017; Van der Sluis et al. 2018) included a fundamentally different use of fuzzy cognitive maps as influence diagrams, with relationships representing the strength rather than the (un)certainty of a connection. Although this is formally a misinterpretation, this type of application is rapidly gaining importance and acceptance among practitioners (see Helfgott et al. 2015). Likewise, the use of directed and signed digraphs (networks with directional edges that have values of \pm 1 ) that are the basis of matrix expert modelling techniques like causal loop diagrams to represent systems of cause-and-effect relationships dates back to Sewall Wright in 1918. Although the use of fuzzy cognitive maps in SES research is relatively new, it is expanding quickly.

The high level of computational requirements for these expert models delayed their common use and restricted the early applications to relatively simple systems. However, modern computing power combined with expanded data libraries and software that emerged over the last decade has enabled the expansion of expert modelling techniques into complex SES (Schlüter et al. 2012).

\section{SES problems and questions}

The inherent complexity of SES makes their behaviour difficult to understand or predict. Modelling tools are indispensable to structure and unravel the complex relationships and therefore increase understanding of the system's behaviour. Complexity furthermore gives 
rise to multiple interpretations and perceptions of how the system works. Expert models are particularly suitable to map out, analyse and compare differences in the perceptions of experts and other stakeholders. It is particularly the combination of understanding system structure and feedback loops and engaging with stakeholders that make expert models an exceptionally strong tool when analysing SES. Key questions include:

- What are different perceptions of key stakeholders? (e.g. understanding the role of landuse intensification in stopping deforestation (Kok 2009), understanding the bushmeat trade based solely on perceived knowledge of stakeholders and combining empirical data with expert knowledge (Htun et al. 2016))

- What are crucial feedbacks in the system? (e.g. understanding how greenhouse gas mitigation and altered hunting practices can increase polar bear persistence (Amstrup et al. 2010), describing the relationship of fish species to financial priorities (Kininmonth et al. 2017))

The particular strength of expert models is the ability to both facilitate fundamental scientific understanding and provide more applied science decision support. These models can be used for initial explorations as well as in-depth analytical assessments, particularly in the realm of using the understanding between system structure and function to support decision-making (Marcot et al. 2006). Unlike many classic statistical approaches, these models can incorporate qualitative and quantitative data types within an interactive framework. This capacity to include empirical and expert-derived data into a comprehensible modelling framework makes the application to SES highly attractive. The transparent nature (being able to see all the components) of the models ensures that stakeholders can gain more confidence in the model outputs while contributing to the model design (Gray et al. 2018). The application to social-ecological models has been hindered only by the access to empirical data that is temporally and spatially relevant to both the ecological and the social domains. However, once sufficient confidence is gained by the analyst in the parameterisation of the models, the generation of projections with estimated levels of certainty is attractive to solve the 'wicked' SES problems (Jentoft and Chuenpagdee 2009).

A particularly useful application of expert models in disentangling SES systems is estimating the impact of scenarios. This allows for extending the understanding of current system perceptions to future configurations and the related impact of external drivers such as climate change or technology development (Jetter and Kok 2014). It also strengthens the link with quantitative models and the comparison with formalised scientific system descriptions in these models (Kok 2009). This capacity to explore the changes in the system can enable the understanding of resilience (Gray et al. 2015) without the constraining simplification of linear models.

\section{Brief description of key methods}

Fuzzy cognitive maps are cognitive maps that structure the opinion of individuals or groups of people, allowing the relationships between factors to be fuzzy, thus calculating the degree of certainty stakeholders have. In particular, the application of fuzzy cognitive maps as influence diagrams has recently gained popularity. In this capacity, system descriptions can be combined with scenario studies (see Chapter 11). Bayesian networks are a method to combine the correlation probability between elements in a system using the simplicity of a network model (see Chapter 23). Hence the calculation of how one element relates to another using Bayes theory is restrained to the network connections. Table 16.1 presents a summary of key methods used in expert modelling. 
Table 16.1 Summary of key methods used in expert modelling

\begin{tabular}{|c|c|c|}
\hline Method & Description & References \\
\hline $\begin{array}{l}\text { Bayesian } \\
\text { networks }\end{array}$ & $\begin{array}{l}\text { A Bayesian network (BN) (or Bayesian belief } \\
\text { network) is the probabilistic graphical model that } \\
\text { represents a set of variables and their conditional } \\
\text { probability with the use of a directed acyclic graph. } \\
\text { In essence, the lines in the network represent the } \\
\text { correlations between the system elements and are } \\
\text { calculated using Bayes theory. Propagating the } \\
\text { correlations across a large number of elements can } \\
\text { be unwieldy and the network restrains the number } \\
\text { of calculations. }\end{array}$ & $\begin{array}{l}\text { Key introductory texts } \\
\text { Marcot 2006; } \\
\text { Rumpff et al. 2011; } \\
\text { Scurati and Denis } 2014 \\
\text { Applications to SES } \\
\text { Stelzenmüller et al. 2010; } \\
\text { Kininmonth et al. 2014; } \\
\text { Gonzalez-Redin et al. 2016; } \\
\text { Kininmonth et al. } 2017\end{array}$ \\
\hline $\begin{array}{l}\text { Dynamic } \\
\text { Bayesian } \\
\text { networks }\end{array}$ & $\begin{array}{l}\text { Dynamic Bayesian networks have temporal } \\
\text { capacity by linking a time sequence within a } \\
\text { probabilistic graphical model. Each time period } \\
\text { has a model of the correlations between elements. } \\
\text { The models then link to replicates of the model in } \\
\text { each time step. The additional complexity of the } \\
\text { temporal linkages restricts the individual model } \\
\text { complexity simply due to the difficulties } \\
\text { in parameterisation. }\end{array}$ & $\begin{array}{l}\text { Key introductory texts } \\
\text { Dean and Kanazawa 1989; } \\
\text { Murphy } 2002 \\
\text { Applications to SES } \\
\text { Pope and Gimblett } 2017\end{array}$ \\
\hline $\begin{array}{l}\text { Fuzzy cognitive } \\
\text { mapping }\end{array}$ & $\begin{array}{l}\text { Fuzzy cognitive mapping (FCM) is a graphical } \\
\text { representation of a belief system comprising } \\
\text { factors and semi-quantified relationships, with the } \\
\text { capacity to examine a variety of scenarios. }\end{array}$ & $\begin{array}{l}\text { Key introductory texts } \\
\text { Kosko 1986; } \\
\text { Özesmi and Özesmi } 2004 \\
\text { Applications to SES } \\
\text { Kok 2009; } \\
\text { Penn et al. 2013; } \\
\text { Diniz et al. 2015; } \\
\text { Gray et al. } 2015\end{array}$ \\
\hline
\end{tabular}

\section{Limitations}

The expert models described here are based on correlations between variables elicited through stakeholder consultation and/or expert design that are perceptual. Resulting system descriptions, therefore, need to be interpreted with caution as they rely on people's perceptions rather than process-based information. This linkage from correlation to causality is particularly perilous when machine learning of the model structure is used. This is because machine learning is based on data (often observed) without any knowledge of process (such as ecological principles), data-collection bias and expert opinion. An additional issue is the application of logical inference over time (see Chapter 27). If one event has an influence on a second event, then the backward inference has to be handled with care as circular arguments through time are often illogical. This is even more dangerous with fuzzy cognitive maps, as 'time' is inadequately defined. If agricultural yield increases, for example, then the area under that crop will increase (due to perceived benefits of that crop by other farmers). In turn, this will lead to an increase in overall yield within the model, without acknowledging the time steps. 


\section{Case study 16.1: Fishers and traders at Lake Nabugabo, Uganda}

In the small lake of Nabugabo, situated close to Lake Victoria, Ugandan fishers collect a small variety of fish species to sell to markets or fish traders (Kininmonth et al. 2017). This case study provides us with an opportunity to understand the cross-scale nature of trading and extraction for an open-access resource. Using Bayesian networks, the microeconomic influences on resource use can be described. Collecting the data was a core activity in this modelling exercise and involved being in the community for extended periods, speaking to fishers and traders about their activities and perceptions. To capture this information in a consistent manner, we used structured interview surveys supplemented with fish-catch observations. These data were a diverse mix of categorical, ordinal and count types and formed the basis of the conceptual model of the fishers and the traders.

The models were used to explore different scenarios of fish-trading styles. While the focus was primarily on the harvest of Nile perch (Lates niloticus) and Nile tilapia (Oreochromis niloticus), the study also collected data on financial, social and ecological dynamics to disentangle the patron-client relationships between traders and fishers. These data ranged from species caught and targeted to the techniques used and the commercial transactions conducted (Figure 16.1). The trading preferences for each fisher and trader were collated and based in a graph theoretical framework where different strategies were observed. Critically, the surveys identified community members who formed the trading relationships.

The results of the study found that if the fishers were incentivised to exchange fish with just one trader ('patron-client') then specific fish species were targeted. If the fisher was able to trade freely ('freelancer') then they were able to create a responsive and flexible extraction practice that matched the market and environmental fluctuations. The use of Bayesian networks enabled a disparate set of data types (from species type, hours spent fishing, to binary yes/no: see Figure 16.1) to be integrated into a quantitative model that could evaluate various scenarios for natural resource extraction.

The model incorporated a diverse and comprehensive parameter set that described the microeconomics of the local fishers at Lake Nabugabo. Scenarios enable the discussion of the effectiveness for management strategies with scope to continue to grow the model with more data (Kleemann et al. 2017).

Figure 16.1 shows the marginal probabilities from the scenario (Kininmonth et al. 2017). Each box in the figure is a system variable that is correlated with a small number of other variables. The arrows highlight the direction of the influence from a Bayesian theory perspective. The rows in the box show the various classes used to group the data while the bars are the frequency of the class. The marginal probability (i.e. no specific case in mind) for the variable 'Gear' shows that 'Gillnet' equipment is used $53.7 \%$ of the time, for example.

The success of projects of this nature depends on the quality of the data collected. The range of respondents needs to be comprehensive for the given set of scenarios and the factors being utilised in the model. In this case, although women were underrepresented in the surveys, partly as a function of their limited role in the physical act of fishing and trading, the central question about microeconomic influences on fishing 
practices does involve women in a variety of roles. Another area of omission is the role of allied industries such as boat construction and repair, and hospitality. Seeking data that can illustrate the linkages across the broader community is useful for socialecological models such as these.

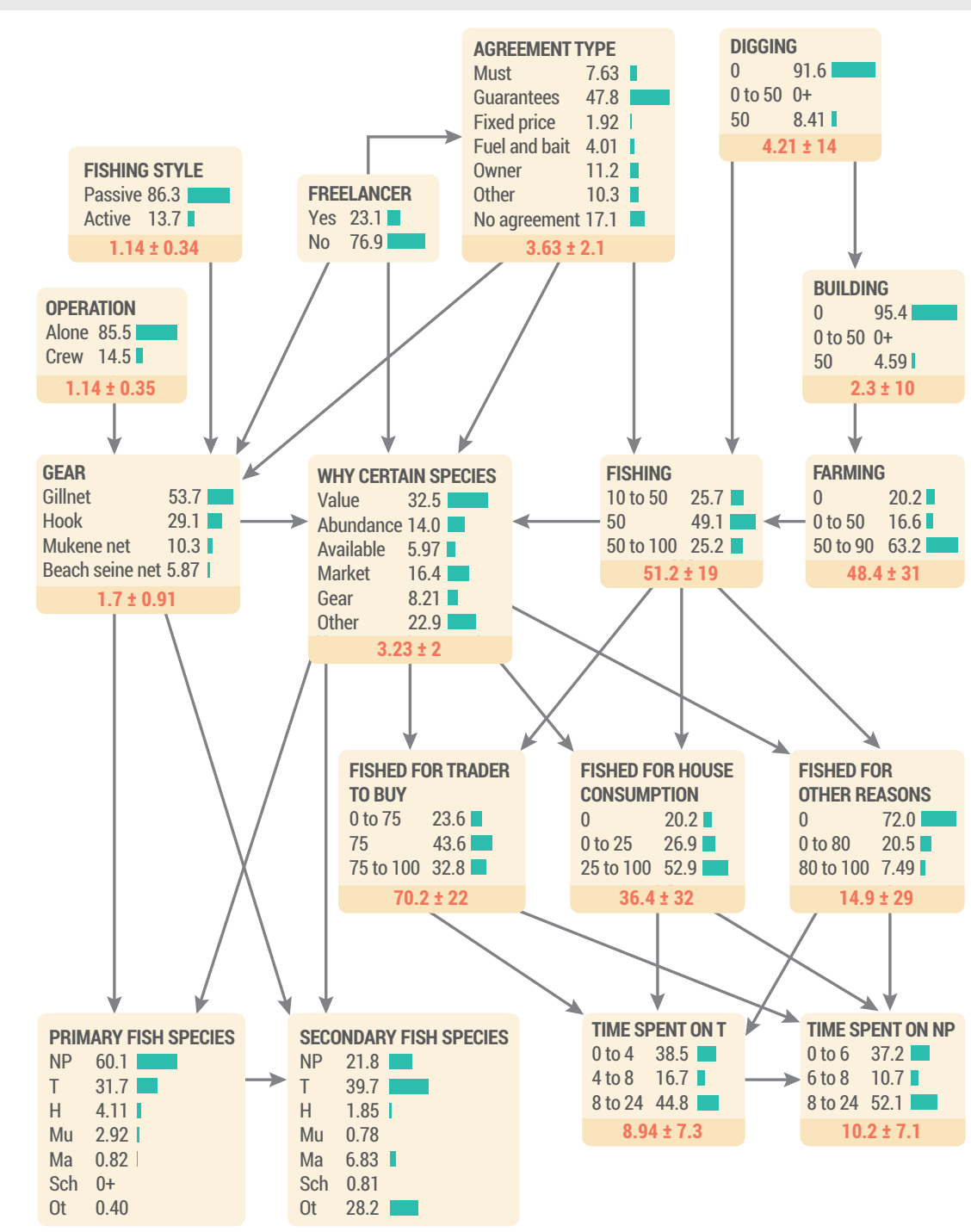

Figure 16.1 Bayesian network of the fisher responses to the questionnaires (Kininmonth et al. 2017) 
The methods are also limited by the scope of either the input data or the cognitive mapping derivation. Evaluation and reflective processes are required at all stages to ensure that the models do not deviate from the accepted wisdom of the operators. This constraint of developing an expert model by contemporary thinking yet still being able to deduce emergent new ideas causes continuous tension. Other limitations for specific methods include a lack of feedback loops for Bayesian networks and a lack of explicit time units for fuzzy cognitive maps. In addition, the central limiting constraint for all expert models is based on obtaining data that cover both social and ecological aspects within a logically coherent time frame and spatial scale. Often the temporal and spatial scales of a social system are different to the key components of an ecological system, and the models need to reflect these assumptions embedded in the deductions.

\section{Resource implications}

The use of expert models requires a modern application of hardware and software that demands advanced skills in both theory and technical implementation. Due to the popularity of expert models over the last few decades, there is a wealth of software to use. This includes graphical user interface (GUI) programs like Netica (Norsys Software Corp), Bayes Fusion, Banjo, BUGS, Dlib, FBN, JavaBayes, SMILE and UnBBayes. In addition, scripting exists in all major languages but particularly in higher-level languages such as $\mathrm{R}$ and Python with packages bnlearn, gRain, abn, catnet and FCMapper.

With new web-enabled technologies, more easy-to-use modelling tools have recently been developed, with some specifically designed for modelling based on diverse expert knowledge. These tools are freely available on the web. Mental Modeler (Gray et al. 2013), for example, has been applied in many participatory SES modelling contexts with both local and scientific experts. These contexts range from fisheries management and agricultural planning to understanding the bushmeat trade. Inputs were based solely on perceived knowledge of stakeholders and combining empirical data with expert knowledge to understand the range of possible futures for endangered wildlife under climate change scenarios (Htun et al. 2016). As 'running' fuzzy cognitive maps relies on rather simple matrix algebra, they can also be developed using a simple Excel spreadsheet. Although this limits flexibility somewhat, it can convince local partners that it really is easy to use and apply.

\section{New directions}

Fuzzy cognitive maps are very strong in describing a system of factors and sectors, but rather weak in representing actors. A very promising way forward is the combination of fuzzy cognitive maps and agent-based models (see Chapter 28), which would allow for actor-specific system descriptions.

The weakest point of fuzzy cognitive maps, the representation of temporal and spatial scales, could be improved by linking them to spatially explicit models, either directly or through the use of scenarios. Scenarios, and particularly future narratives or normative strategies, often remain qualitative and based on current systems understanding. Methods to construct fuzzy cognitive maps of future systems perceptions are underdeveloped and could play a role, e.g. in today's discussions of societal transformation to meet the goal of limiting global warming to $1.5^{\circ} \mathrm{C}$.

The exciting development in this field is the accumulation of data that are specifically captured to address strategic questions. These data can be used to develop more powerful expert models since the parameterisation process is significantly more precise. The model design and 
style are continually evolving with exciting developments in the use of machine learning to disentangle patterns in data. However, the imperative to understand complex behaviour of SES, including predicting tipping points and understanding disturbance events, continues to demand additional modelling and data-collection techniques.

\section{Key readings}

Gray, S.A., S. Gray, J.L. de Kok, A.E.R. Helfgott, B. O’Dwyer, R. Jordan, and A. Nyaki. 2015. ‘Using Fuzzy Cognitive Mapping as a Participatory Approach to Analyze Change, Preferred States, and Perceived Resilience of Social-Ecological Systems.' Ecology and Society 20(2): 11. doi:10.5751/ ES-07396-200211.

Marcot, B. G., R.S. Holthausen, M.G. Rowland, and M.J. Wisdom. 2001. 'Using Bayesian Belief Networks to Evaluate Fish and Wildlife Population Viability under Land Management Alternatives from an Environmental Impact Statement.' Forest Ecology and Management 153: 29-42. doi:10.1016/ S0378-1127(01)00452-2.

Rumpff, L., D.H. Duncan, P.A. Vesk, D.A. Keith, and B.A. Wintle. 2011. 'State-and-transition Modelling for Adaptive Management of Native Woodlands.' Biological Conservation 144: 1224-1236.

\section{Acknowledgements}

We particularly want to thank Andrew Byekwaso for conducting the questionnaires, and Dennis Twinomugisha for assistance with the field programme outlined in the Kininmonth et al. (2017) case study. This work was partially supported by Mistra through a core grant to the Stockholm Resilience Centre and the Strategic Research Programme EkoKlim.

\section{References}

Amstrup, S.C., E.T. DeWeaver, D.C. Douglass, B.G. Marcot, G.M. Durner, C.M. Bitz, and D.A. Bailey. 2010. 'Greenhouse Gas Mitigation Can Reduce Sea-Ice Loss and Increase Polar Bear Persistence.' Nature 468: 955-958. doi:10.1038/nature09653.

Axelrod, R. 1976. Structure of Decision: The Cognitive Maps of Political Elites. Princeton: Princeton University Press. doi:10.2307/1955121.

Dean, T., and K. Kanazawa. 1989. 'A Model for Reasoning about Persistence and Causation.' Artificial Intelligence 93(1-2): 1-27.

Diniz, F.H., K. Kok, M. Hoogstra-Klein, and B. Arts. 2015. 'Mapping Future Changes in Livelihood Security and Environmental Sustainability Based on Perceptions of Small Farmers in the Brazilian Amazon.' Ecology and Society 20(2): 26. doi:10.5751/ES-07286-200226.

Gonzalez-Redin, J., S. Luque, L. Poggio, R. Smith, and A. Gimona, A. 2016. 'Spatial Bayesian Belief Networks as a Planning Decision Tool for Mapping Ecosystem Services Trade-Offs on Forested Landscapes.' Environmental Research. doi:10.1016/j.envres.2015.11.009.

Gray, S., L. Cox, and S. Henly-Shepard. 2013. 'Mental Modeler: A Fuzzy-logic Cognitive Mapping Modeling Tool for Adaptive Environmental Management.' Proceedings of the 46th International Conference on Complex Systems. doi:10.1109/HICSS.2013.399.

Gray, S.A., S. Gray, J.L. de Kok, A.E.R. Helfgott, B. O’Dwyer, R. Jordan, and A. Nyaki. 2015. 'Using Fuzzy Cognitive Mapping as a Participatory Approach to Analyze Change, Preferred States, and Perceived Resilience of Social-Ecological Systems.' Ecology and Society 20(2): 11. doi:10.5751/ ES-07396-200211.

Gray, S., A. Voinov, M. Paolisso, R. Jordan, T. BenDor, P., Bommel, P. Glynn et al. 2018. 'Purpose, Processes, Partnerships, and Products: Four Ps to Advance Participatory Socio-environmental Modeling.' Ecological Applications 28(1): 46-61.

Helfgott, A., S. Lord, N. Bean, M. Wildenberg, S. Gray, S. Gray, J. Vervoort, K. Kok, and J. Ingram. Submitted. 2015. 'Clarifying Fuzziness: Fuzzy Cognitive Maps, Neural Networks and System Dynamics Models in Participatory Social and Environmental Decision-aiding Processes.' Transmango Working Paper 1, Brussels: EC. 
Htun, H., S.A. Gray, C.A. Lepczyk, A. Titmus, and K. Adams. 2016. 'Combining watershed models and knowledge-based models to predict local-scale impacts of climate change on endangered wildlife.' Environmental Modelling and Software 84: 440-457.

Jackson, P. 1998. Introduction to Expert Systems (3rd ed). Boston: Addison-Wesley.

Jentoft, S., and R. Chuenpagdee. 2009. 'Fisheries and Coastal Governance as a Wicked Problem.' Marine Policy 33: 553-560.

Jetter, A.J., and L. Kok. 2014. 'Fuzzy Cognitive Maps for Futures Studies. A Methodological Assessment of Concepts and Methods.' Futures 61: 45-57. doi:10.1016/j.futures.2014.05.002.

Kininmonth, S., B. Crona, Ö. Bodin, I. Vaccaro, L. Chapman, and C. Chapman. 2017. 'Microeconomic Relationships between and among Fishers and Traders Influence the Ability to Respond to Social-Ecological Changes in a Small-scale Fishery.' Ecology and Society 22(2): 26.

Kininmonth, S., S. Lemm, M. Cherie, and T. Hatley. 2014. 'Spatial Vulnerability Assessment of Anchor Damage within The Great Barrier Reef World Heritage Area.' Ocean and Coastal Management 100: 20-31.

Kleemann, J., E. Celio, B.K. Nyarko, M. Jiménez-Martínez, and C. Fürst. 2017. 'Assessing the Risk of Seasonal Food Insecurity with an Expert-based Bayesian Belief Network Approach in Northern Ghana, West Africa.' Ecological Complexity 32: 53-73.

Kok, K. 2009. 'The Potential of Fuzzy Cognitive Maps for Semi-quantitative Scenario Development, with an Example from Brazil.' Global Environmental Change 19: 122-133.

Kosko, B. 1986. 'Fuzzy Cognitive Maps.' International Journal of Man-Machine Studies 24: 65-75.

Marcot, B.G., J.D. Steventon, G.D. Sutherland, and R.K. McCann. 2006. 'Guidelines for Developing and Updating Bayesian Belief Networks Applied to Ecological Modeling and Conservation.' Canadian Journal of Forest Research 36: 3063-3074.

Murphy, K.P. 2002. 'Dynamic Bayesian Networks: Representation, Inference and Learning.' PhD diss., University of California Berkeley.

Özesmi, U., and S.L. Özesmi. 2004. 'Ecological Models Based on People's Knowledge: A Multistep Fuzzy Cognitive Mapping Approach.' Ecological Modelling 176: 43-64. doi:0.1016/j. ecolmodel.2003.10.027.

Pearl, J. 1982. 'Reverend Bayes on Inference Engines: A Distributed Hierarchical Approach.' AAAI-82Proceedings. https://aaai.org/Papers/AAAI/1982/AAAI82-032.pdf.

Penn, A.S., C.J.K. Knight, D.J.B Lloyd, D. Avitabile, K. Kok, F. Schiller, A. Woodward, A. Druckman, and L. Basson. 2013. 'Participatory Development and Analysis of a Fuzzy Cognitive Map of the Establishment of a Bio-Based Economy in the Humber Region.' PLoS ONE 8(11): e78319.

Pope, A., and H.R. Gimblett. 2017. 'Linking Bayesian and Agent-based Models to Simulate Complex Social-Ecological Systems in Semi-arid Regions.' In Hybrid Solutions for the Modelling of Complex Environmental Systems, edited by C.E. Vincenot, S. Mazzoleni, and L. Parrott. Frontiers e-Books.

Rumpff, L., D.H. Duncan, P.A. Vesk, D.A. Keith, and B.A. Wintle. 2011. 'State-and-transition Modelling for Adaptive Management of Native Woodlands.' Biological Conservation 144: 1224-1236.

Schlüter, M., R.R.J. McAllister, R. Arlinghaus, N. Bunnefeld, L. Eisenack, F. Holker, E. MilnerGulland et al. E. 2012. 'New Horizons for Managing the Environment: A Review of Coupled Social-Ecological Systems Modeling.' Natural Resource Model 25: 219-272.

Scurati, M., and J-B. Denis. 2014. Bayesian Networks: With Examples in R. Boca Raton: CRC Press.

Stelzenmüller, V., J. Lee, E. Garnacho, and S.I. Rogers. 2010. 'Assessment of a Bayesian Belief Network-GIS Framework as a Practical Tool to Support Marine Planning.' Marine Pollution Bulletin 60: 1743-1754.

Van der Sluis, T., M. Bogers, K. Kok, G. Cosor, N. Geamana, E. Crouzat, E. Pavlis et al. 2018. 'Drivers of European Landscape Change: Stakeholders' Perspectives through Fuzzy Cognitive Mapping.' Landscape Research. doi:10.1080/01426397.2018.1446074.

Van Vliet, M., K. Kok, and T. Veldkamp. 2010. 'Linking Stakeholders and Modellers in Scenario Studies: The Use of Fuzzy Cognitive Maps as a Communication and Learning Tool.' Futures 42(1): 1-14.

Verkerk, P.H., A. Sánchez, S. Libbrecht, A. Broekman, A. Bruggeman, H. Daly-Hassen, E. Giannakis et al. 2017. 'A Participatory Approach for Adapting River Basins to Climate Change.' Water 9: 958. doi:10.3390/w9120958. 